\title{
Effect of Silver Diamine Fluoride Pretreatment on Shear Bond Strength of Resin Modified Glass lonomer Cement to Primary Dentin
}

\author{
Maiada Mohammad Ahmad Sa'ada ${ }^{1 *}$, Nagwa Mohammed Ali Khattab ${ }^{2}$, Maha Ishaq Amer ${ }^{3}$ \\ ${ }^{1}$ Department of Pediatric and Community Dentistry, Faculty of Dentistry, Assiut University, Assiut, Egypt; ${ }^{2}$ Department of \\ Pediatric Dentistry and Dental Public Health, Faculty of Dentistry, Ain Shams University, Cairo, Egypt; ${ }^{3}$ Department of Oral and \\ Maxillofacial Radiology, Faculty of Dentistry, Minia University, Minia, Egypt
}

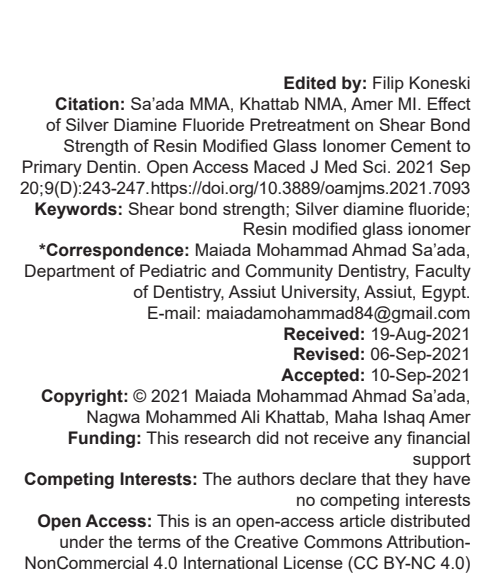

\section{Introduction}

Dental caries is one of the most common preventable diseases which are recognized as the primary cause of oral pain and tooth loss. It is a major public health oral disease that hinders the achievement and maintenance of oral health in all age groups [1]. Caries can be prevented and arrested using fluoride-based materials such as professional applied varnishes. Silver diamine fluoride (SDF) has been used for arresting dental caries in children worldwide since the early 1960s, cleared by the Food and Drug Administration in the United States in 2014 and in 2015 that product is available [2], [3], [4].

SDF inhibits cariogenic biofilm formation, generates a highly remineralized dentin surface, rich in calcium and phosphate ions so it can be used in both prevention of and arresting caries. Furthermore, SDF possesses an antimicrobial activity against cariogenic bacteria such as Streptococcus mutans or Actinomyces naes/undii formed on dentine surfaces. It also believed to inhibit dentine demineralization, preserve collagen from degradation in demineralized dentine and increase the $\mathrm{pH}$ of biofilm [5], [6], [7]. It has been used in primary teeth especially in conditions such as early childhood caries, patients suffering from behavioral or medical issues that make conventional therapy impossible, patients with special needs, those with salivary dysfunction, and those who cannot afford or have regular dental services. It also has been used to control dental caries, especially in pre-school children with dentine caries lesions as it is safe, efficient, viable, and effective in arresting dentine caries [8], [9]

SDF darkens the carious lesions. It causes a "temporary tattoo" to skin (on the patient or provider) which resolves within 2-14 days. A transient metallic or bitter taste was reported but it is still more favorable than that caused by the fluoride varnish [10]. Alternative ways were introduced to mask the black discoloration of the tooth surface that is a result of silver precipitate.

Addition of saturated potassium iodide solution (KI) before SDF treatment to react with free silver ions to form a creamy white product which is silver iodide 
that decreased the intensity of staining but negatively affected the adhesion of resin-based adhesives and RMGIC to dentin [11], [12].

Furthermore, application of composite or glassionomer cement (GIC) restorations after the application of SDF will mask the black color of the carious lesion for better aesthetics, improve chewing ability, prevent food accumulation and, so, maintain adequate oral hygiene. This technique is known as silver modified atraumatic restorative technique [13].

The bond strengths of composite to sound primary molars were negligibly affected by the pretreatment of the primary dentin with 38\% SDF as cleared by Wu et al. while Fröhlich et al. in systematic review and meta-analysis (2019) found that the previous application of SDF does not influence the dentine bond strength of GIC but compromises the bonding of adhesive systems [14], [15]. Therefore, the aim of the current study was to evaluate shear bond strength (SBS) of RMGIC to primary dentin after SDF pre-treatment.

\section{Materials and Methods}

This study was approved by Research Ethical Committee of Faculty of Dentistry, Minia University. (No: 329-3/2019).

\section{Sample size}

Using a power of $94 \%$, a sample size of ten specimens per group was the minimum required and it was calculated using IBM SPSS sample power program version 3.0.1.

\section{Teeth selection and preparation}

Twenty sound primary molars with no restorations or developmental anomalies were only chosen for the study. Teeth were cleaned with deionized water and stored in a $0.1 \%$ thymol solution at $4^{\circ} \mathrm{C}$ for a maximum of 1 month.

\section{Specimen preparation}

Twenty dentine slices with $2 \mathrm{~mm}$ thickness were prepared from 20 sound primary molars using a low-speed saw with a diamond blade (ISOMET 1000; Buehler, Lake Bluff, IL, USA) to obtain flat dentin surface and the roots were cutoff $2 \mathrm{~mm}$ below the cemento-enamel junction using diamond disc bur under water coolant. All dentine slices were embedded in a dental cold cured acrylic mold (ProBase Cold, Ivoclar Vivadent AG, and Liechtenstein). The surfaces of the dentine slices were polished with micro-fine 2000-grit sanding paper under running water.

\section{Grouping}

Dentine specimens were randomly allocated into two groups ( $\mathrm{n}=10$ per group).

Group 1 (experimental): Dentine surfaces were treated with $38 \%$ *SDF solution (Elevate oral care, USA) for 3 min using micro-brush, followed by a $30 \mathrm{~s}$ rinse with water.

Group 2 (Control): Dentine surfaces were treated with distilled water for 3 min then rinsed for $30 \mathrm{~s}$.

Then, the cavity conditioner was applied to flat dentin of both groups for $10 \mathrm{~s}$ then washed and dried gently with compressed air.

To create a standardized bonding area, a plastic cylindrical shaped mold with internal diameter of $3 \mathrm{~mm}$ and height of $2 \mathrm{~mm}$ was placed at right angle on the cut surface of the polished flat dentin and filled with *RMGIC (Riva Light Cure, SDI, Australia) in increments then each one was light cured for 20 $s$ according to manufacturer's instructions for both groups.

\section{Testing of SBS}

The SBS was assessed using Universal Testing machine Instron industrial production, USA (Norwood). Shear load was directed parallel to the bonded interface with a sharp blade at cross head speed of $0.5 \mathrm{~mm} / \mathrm{min}$ until failure occurred.

The following equation was used to calculate the SBS:

SBS in Megapascals $(\mathrm{MPa})=$ the maximum failure load in Newtons $(\mathrm{N})$ /surface area of the bonded interface $\left(\mathrm{mm}^{2}\right)$. The surface area $(A)$ was calculated from the following equation: $A=\pi r^{2}$ where $\pi$ is a constant value $=3.14$ and $r$ is radius .

Failure modes were evaluated by a single examiner (demonstrator at Dental Biomaterial Department, Minia University) using stereomicroscope at $\times 40$ magnification, and classified as: Adhesive (failure at the interface of RMGIC and the dentin surface), Cohesive (failure within the dentin or RMGIC), and Mixed (combination of adhesive and cohesive failure).

\section{Statistical methods}

Independent $\mathrm{t}$ test was used to assess differences in SBS between study groups while Fisher's exact test was used to assess mode of failure. Level of significance was set at $p \leq 0.05$. IBM SPSS statistical software (version 26) was used to analyze the data. 


\section{Results}

\section{Shear bond assessment}

SBS evaluation represented a mean of $11.92 \pm 3.35 \mathrm{MPa}$ in the experimental group and $6.99 \pm 2.98 \mathrm{MPa}$ in the control group. The highest bond strength value was recorded in the SDF pretreated group while the lowest SBS value was recorded in the control group. Using independent $t$ test, 38\% SDF pre-treated primary dentin presented statistically significant higher bond strength $(p=0.003)$.

Table 1: Comparison of the shear bond strength assessment in the groups

\begin{tabular}{lll}
\hline Groups & Mean \pm SD & p-value \\
\hline Experimental group & $11.92 \pm 3.35$ & 0.003 \\
Control group & $6.99 \pm 2.98$ & \\
\hline
\end{tabular}

Comparison of the SBS assessment in the groups was done using an independent samples $\mathrm{t}$ test. A statistically significant difference was observed between the groups.

Descriptive statistics of the SBS (MPa) of the experimental and control groups are illustrated in Table 1 and Figure 1.

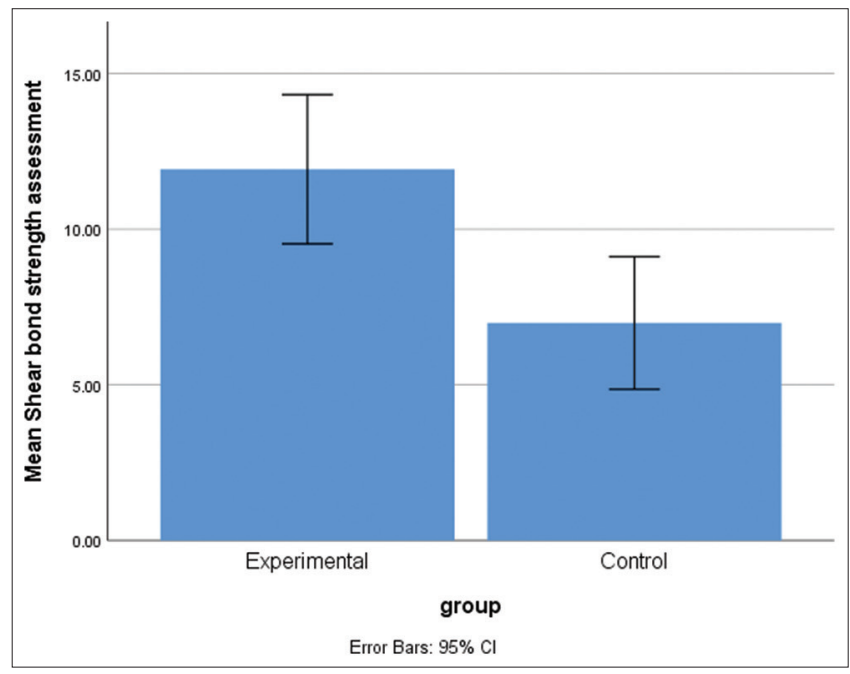

Figure 1: Bar graph error for shear bond strength in the studied groups

Comparison of the failure mode assessment in the groups was done using Fisher's exact test. There was no statistically significant difference between the two groups, $p=0.070$ (Table 2).

Table 2: Comparison of the failure mode assessment in the groups

\begin{tabular}{llll}
\hline Groups & \multicolumn{2}{c}{ Failure mode assessment } & p-value \\
\cline { 2 - 3 } & Adhesive & Mixed & \\
\hline Experimental group $\mathrm{n} \%$ & 3 & 7 & 0.070 \\
& $30.0 \%$ & $70.0 \%$ & \\
Control group $\mathrm{n} \%$ & 8 & 2 & \\
& $80.0 \%$ & $20.0 \%$ & \\
\hline
\end{tabular}

Most of failures were classified as mixed mode $(70 \%)$ in Group 1 (38\% SDF pre-treated) and adhesive mode (80\%) i n Group 2 (control group) (Figures 2 and $3 a$ and $b$ ).

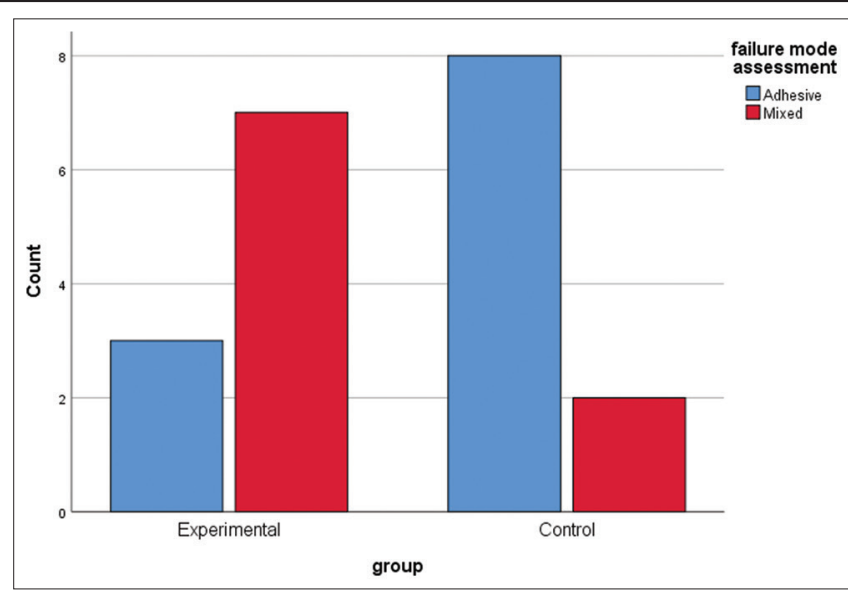

Figure 2: Bar graph for failure mode assessment in the groups

\section{Discussion}

Dental caries is a very common and prevalent disease especially in pre-school age children. Treatment of caries with the conventional methods requires cooperation of the child, well trained and experienced dentist, and special equipment and materials and hence this will be cost effective [4], [16].

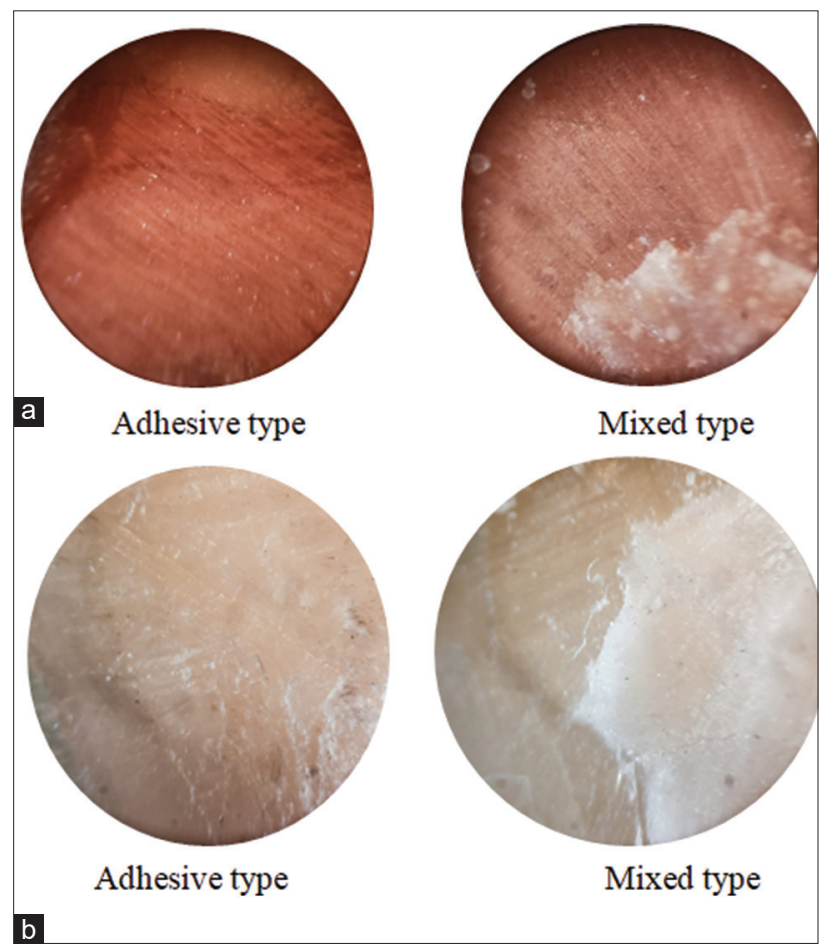

Figure 3: Failure mode assessment (a) experimental group (b) control group)

Scoping on prevention or arresting of caries is better than complete removal of caries. Accordingly, fluoride-based materials started to be used in 1891 "Howe's solution" which is a mixture of nitric acid and amalgam scraps (silver nitrate solution) was used to inhibit caries progression in children of Boston, USA [3], [17].

SDF is used for several years ago and has promising results in prevention and arresting caries. It is only blamed for discoloration of tooth 
structure which negatively affects patient and parent satisfaction [18].

From this point, our study was to restore SDF pre-treated tooth with RMGIC and compare it to control group that is RMGIC and evaluate if SDF impairing SBS to primary dentine or not beside determining failure mode.

SDF has multiple concentrations available in the market. At this study, $38 \%$ was used according to Fung et al. who concluded that SDF $38 \%$ conc. was more effective in prevention and arresting of caries than $12 \%$ conc. [19].

To standardize the current study, only sound primary molars with no restorations or developmental anomalies were chosen for the study. Teeth were cleaned with deionized water and stored in a $0.1 \%$ thymol solution for $4^{\circ} \mathrm{C}$ before section a maximum 1 month then randomly allocated into two groups $n=10$. The randomization was done using random allocation software program into two groups. Group 1 (experimental group): The cavities were treated with $38 \%$ SDF solution (Elevate oral care, USA) while Group 2 (control group): Cavities were only treated with distilled water [20].

According to the results of this study, it was found that pre-treatment of sound primary dentin with SDF increased significantly SBS between RMGIC and the primary dentin. Mixed type of failure was predominant in the experimental group while adhesive type of failure was predominant in the control group and the difference between the two groups was nonsignificant. The observed mode of failure indicates that the retentive strength between SDF pre-treated primary dentin and RMGIC was greater than that in the control group. This is supported by Fröhlich et al., who said in a systematic review that silver phosphate restores the mineral content and so re-hardening of the soft tooth structure while silver ions precipitate strengthens ionic bond to GIC and so enhance bond strength to dentine of primary teeth. On the other hand, cohesive failure within GICs was the most common fracture mode between GICs and dentine in a study done by Tanumiharja et al., whereas this type of failure was less frequent absent in both groups in the present study. This variance might be explained by the different experimental conditions [15], [21].

Furthermore, it was revealed that dentin surface darkened more when SDF was light cured which indicates more precipitation of more metallic silver increasing the ionic interaction between GIC and dentin. Moreover, light curing of the RMGIC for 20 s may increase the SBS between SDF pre-treated primary dentin and RMGIC since Wang et al. founded that demineralized dentin treated with SDF then light cured had higher SBS than demineralized dentin treated with SDF without light curing or not treated at all [22].

This study is in one line with Gupta et al. who concluded that SDF-KI application increased the bond strength of RMGIC to dentine. Besides, Soliman et al. concluded that SBS for SDF 38\% pre-treated teeth increased [23], [24].

Furthermore, Pérez-Hernández et al. founded that SDF increases adhesion of pit and fissure sealant to tooth structure [25].

On the other hand, François et al. founded that no significant differences in SBS for EQUIA Forte bound to sound dentin using SDF [26].

The strength of the in vitro experimental study achieved by being carried out in laboratory conditions. This removed the possibility of clinical errors such as limited mouth opening, moisture control, and standardized size of specimen.

However, the limitation of the study includes the difficulty to simulate the oral conditions regarding the biological aspects of caries and many factors that may contribute to bond strength in vital tooth.

\section{Conclusion}

- $\quad$ According to this in vitro study, SBS for SDF group was significantly higher than that of the control group

- $\quad$ SDF could enhance bond strength to primary dentine

In vivo studies are recommended to evaluate SBS in oral conditions.

\section{References}

1. Thean $\mathrm{H}$, Wong $\mathrm{ML}$, Koh $\mathrm{H}$. The dental awareness of nursing home staff in Singapur-a pilot study. Gerodontology. 2007; 24(1):58-63. https://doi.org/10.1111/j.1741-2358.2007.00138.x PMid:17302933

2. American Dental Association Council on Scientific Affairs. Professionally applied topical fluoride: Evidence-based clinical recommendations. J Am Dent Assoc. 2006; 137(8):1151-9. https://doi.org/10.14219/jada.archive.2006.0356

PMid: 16873333

3. Horst JA, Ellenikiotis H, Milgrom PL. UCSF protocol for caries arrest using silver diamine fluoride: Rationale, indications, and consent. J Calif Dent Assoc. 2016; 44(1):16-28. PMid:26897901

4. Rosenblatt A, Stamford T, Niederman R. Silver diamine fluoride: A caries "silver-fluoride bullet". J Dent Res. 2009; 88(2):116-25. https://doi.org/10.1177/0022034508329406. PMid:19278981

5. World Health Organization. WHO Expert Consultation on Public Health Intervention against Early Childhood Caries: Report of a Meeting, Bangkok, Thailand. Geneva: World Health Organization; 2017. Available from: https://www.apps.who.int/ iris/handle/10665/255627. [Last accessed on 2021 May17]. 
6. Chu $\mathrm{CH}$, Mei L, Seneviratne CJ, Lo EC. Effects of silver diamine fluoride on dentine carious lesions induced by Streptococcus mutans and Actinomyces naeslundii biofilms. Int J Paediatr Dent. 2012; 22(1):2-10. https:// doi. org/10.1111/j.1365-263X.2011.01149.x

\section{PMid:21702854}

7. Mei ML, Ito L, Cao Y, Lo EC, Li QL, Chu CH. An ex vivo study of arrested primary teeth caries with silver diamine fluoride therapy. J Dent. 2014; 42(4):395-402. https:// doi. org/10.1016/j. jdent.2013.12.007.

PMid:24373856

8. Mei ML, Li QL, Chu CH, Yiu CK, Lo EC. The inhibitory effects of silver diamine fluoride at different concentrations on matrix metalloproteinases. Dent Mater. 2012; 28(8):903-8. https:// doi. org/10.1016/j.dental.2012.04.011

PMid:22578660

9. Mei ML, Ito L, Cao Y, Li Q, Lo EC, Chu C. Inhibitory effect of silver diamine fluoride on dentine demineralization and collagen degradation. J Dent. 2013; 41(9):809-17. https:// doi org/10.1016/j.jdent.2013.06.009

PMid:23810851

10. Mei ML, Chu CH, Lo EC, Samaranayake LP. Fluoride and silver concentrations of silver diamine fluoride solutions for dental use. Int J Paediatric Dent. 2013; 23(4):279-85. https:// doi. org/10.1111/ipd.12005. PMid:23033939

11. Suzuki T, Nishida M, Sobue S, Moriwaki Y. Effects of diammine silver fluoride on tooth enamel. J Osaka Univ Dent Sch. 1974; 14:61-72.

\section{PMid:4535096}

12. Chu $\mathrm{CH}$, Lo EC. Microhardness of dentine in primary teeth after topical fluoride applications. J Dent. 2008; 36(6):387-91. https:// doi.org/10.1016/j.jdent.2008.02.013

PMid:18378377

13. Zhao IS, Chu S, Yu OY, Mei ML, Chu CH, Lo EC. Effect of silver diamine fluoride and potassium iodide on shear bond strength of glass ionomer cements to caries-affected dentine. Int Dent J. 2019; 69(5):341-7. https://doi.org/10.1111/idj.12478 PMid:30892699

14. Wu DI, Velamakanni S, Denisson J, Yaman P, Boynton JR, Papagerakis P. Effect of silver diamine fluoride (SDF) application on microtensile bonding strength of dentin in primary teeth. Pediatr Dent. 2016; 38(3):148-53.

PMid:27097864

15. Fröhlich TT, Rocha RD, Botton G. Does previous application of silver diammine fluoride influence the bond strength of glass ionomer cement and adhesive systems to dentin? Systematic review and meta-analysis. Int J Paediatr Dent. 2019; 30:85-95. https://doi.org/10.1111/ipd.12571

PMid:31419356

16. Rencken JE, Sharma P, Stenhouse L, Green D, Laverty D, Dietrich T. Global epidemiology of dental caries and severe periodontitis-a comprehensive review. J Clin Periodontol.
2017; 44 Suppl 18:S94-105. https://doi.org/10.1111/ jcpe. 12677.

PMid:28266116

17. Howe PR. A method of sterilizing and at the same time impregnating with a metal affected dentinal tissue. Dent Cosmos. 1917; 59(9):891-904.

18. Shounia TY, Atwan S, Alabduljabbar R. Using silver diamine fluoride to arrest dental caries: Anew approach in the US. J Dent Oral Biol. 2017; 2(18):1105.

19. Fung $\mathrm{MH}$, Duangthip $\mathrm{D}$, Wong $\mathrm{MC}$, Lo $\mathrm{EC}$, Chu $\mathrm{CH}$. Randomized clinical trial of $12 \%$ and $38 \%$ silver diamine fluoride treatment. J Dent Res. 2018; 97(2):171-8. https:// doi. org/10.1177/0022034517728496 PMid:28846469

20. Puwanawiroj A, Trairatvorakul C, Dasanayake AP, Auychai P. Microtensile bond strength between glass ionomer cement and silver diamine fluoride-treated carious primary dentin. Pediatr Dent. 2018; 40(4):291-5.

PMid:30345969

21. Tanumiharja M, Burrow MF, Tyas MJ. Microtensile bond strengths of glass ionomer (polyalkenoate) cements to dentine using four conditioners. J Dent. 2000; 28(5):361-6. https:// doi. org/10.1016/s0300-5712(00)00009-9

PMid:10785303

22. Wang AS, Botelho MG, Tsoi JK, Matinlinna JP. Effects of silver diammine fluoride on microtensile bond strength of GIC to dentine. Int J Adhes Adhes. 2016; 70:196-203. https:// doi. org/10.1016/j.ijadhadh.2016.06.011

23. Jaivrat G, Manuel ST, Radhakrishna M, Srikant N, Kishore G. Effect of silver diamine fluoride-potassium iodide and $2 \%$ chlorhexidine gluconate cavity cleansers on the bond strength and microleakage of resin-modified glass ionomer cement. J Conserv Dent. 2019; 22(2):201-6. https://doi.org/10.4103/ JCD.JCD_485_18

PMid:31142994

24. Soliman N, Bakry N, Mohy El Din MH, Talat, D. Effect of silver diamine fluoride pretreatment on microleakage and shear bond strength of resin modified glass ionomer cement to primay dentin (in vitro study). Alexandria Dent J. 2021;1-6. https://doi. org/10.21608/adjalexu.2020.35954.1085 article in press.

25. Pérez-Hernández J, Aguilar-Díaz FC, Venegas-Lancón RD, Gayosso CA, Villanueva-Vilchis MC, de la Fuente-Hernández J. Effect of silver diamine fluoride on adhesion and microleakage of a pit and fissure sealant to tooth enamel: In vitro trial. Eur Arch Paediatr Dent. 2018; 19(6):411-6. https://doi.org/10.1007/ s40368-018-0374-4

PMid:30324562

26. François P, Greenwall-Cohen J, Le Goff S, Ruscassier N, Attal JP, Dursun E. Shear bond strength and interfacial analysis of high-viscosity glass ionomer cement bonded to dentin with protocols including silver diammine fluoride. J Oral Sci. 2020; 62(4):444-8. https://doi.org/10.2334/ josnusd.20-0065

PMid:32879159 